\title{
Mature Taiwanese Writers' Development of Writing and Voices between Different Academic Environments
}

\author{
Shu-Fen Yeh \\ Department of Applied English, Shih Chien University \\ 200 University Road, Neimen, Kaohsiung 84550 Taiwan, R.O.C. \\ E-mail: susanyeh@g2.usc.edu.tw
}

Doi:10.7575/aiac.alls.v.6n.5p.197

Received: 03/05/2015

URL: http://dx.doi.org/10.7575/aiac.alls.v.6n.5p.197

Accepted: 04/08/2015

\begin{abstract}
The present study explores four L2 mature writers' development of writing and voices in English between different academic environments, and seeks to create more meaningful grounds for teaching academic ESL writing in the U.S. and college writing in Taiwan. The approach of this study is influenced by Hirvela and Belcher's (2001) reading of terms they define as voicist - in other words, terms that refer to voices and identities. Qualitative research methodology is adequate for this exploratory study because of its capacity to gain in-depth and interpretive understanding of the composing process that second language writers employ in different contexts. The study results have highlighted some of the major challenges of academic writing Taiwanese L2 writers encounter when studying abroad at graduate level. One of the salient problems is inadequate academic writing skills, and the sub-problem is a failure to express ideas with a strong individual voice and to position themselves appropriately in their texts (e.g. having a narrow scope of positioning themselves, applying limited linguistic features to position themselves and lacking confidence to express their ideas and to position themselves in texts).As a result, they face great challenges in the Western educational system, but with their development of academic writing skills, voice, critical thinking through academic writing practices, L2 writers can overcome the challenges and become successful writers which can in turn lead to successful academic careers and publishing.
\end{abstract}

Keywords: Second language writing, voice and positioning, academic writing

\section{Introduction}

As numbers of international graduate students in North American institutions have increased over the last 25 years, research attention on second language writing has increased sharply and begun to shift the primary focus from second language learner (L2) undergraduates to the L2 graduate student population (Leki et al., 2008). Many L2 scholars and educators claim that those diverse groups of ESL students represent social, political, cultural, and educational ideologies informing literacy practices (e.g. Gee, 1996), and that their prior academic writing practices are significant in informing their current writing practices and influencing their writing development. Therefore, Matsuda (1998) has called for research on ESL writers from diverse backgrounds, with a view toward understanding them as writers and exploring how their past educational backgrounds have impacted their writing in different academic contexts.

Many international students arrive in graduate school in the United States as already highly respected and established professionals in their home countries. Even though these students have a high degree of disciplinary knowledge, experience writing within their disciplines in L1, and a background of reading in English, they still need to face the challenge of learning between different academic environments. Many of these graduate students face the challenge of adapting to a new context in which the educational system and culture are strongly linked with the ideology of individualism. Therefore, many scholars have researched the dilemmas and struggles faced by L2 English writers from different cultures and linguistic backgrounds.

In recent times, the notion of written voice also has played an important role in the progress of writing research and instruction in L2 domains (e.g. Atkinson, 2001; Belcher \& Hirvela, 2001; Ivanic \& Camps, 2001; Ivanic, 1998; Matsuda, 2001; Matsuda \& Tardy, 2007; Prior, 2001) and in academic writing (Ivanic, 1998). L2 researchers argue for a strong link between the concept of individualism in compositional pedagogy and the assessment of text, which can be confusing and difficult for L2 writers who have come from collectivist cultures such as Japan, China, Taiwan and other Asian countries. Writing research, therefore, addresses the significant concepts of voice and identity, and writing instructors often speak of the need to help students acquire a voice or identity. It is a big challenge for L2 students who have had limited previous cultural exposure to individual expression and argumentation to expect these students to reorient themselves to values found in Western cultures. Therefore, it is important for writing instructors to encourage L2 students to use their own voice (both personal and academic) without infringing on their own culturally-based beliefs about self and identity.

Due to the shortage of existing research about L2 writers' development of voices between different academic 
environments, particularly focusing on a group of mature writers, it is necessary for writing researchers and scholars to look at this group of participants and to focus on insights that can inform writing program development, and target the writing needs of these L2 writers. Therefore, the purpose of the study was to hear the voices of individual NNS (NonNative Speaker) professional writers in their development of academic writing in English and how they developed their written voice between different academic environments. This study is a baseline study that seeks to fill the current gap in research with a group of Taiwanese mature writers with regard to their current academic writing practices, voicerelated experiences and problems, and their writing developments between different academic environments.

\section{Literature Review}

\subsection{Voice in English (L1) Composition Pedagogy}

Voice has played an important role in composition pedagogy since the 1970s and remains popular in the United States. In the early 1970's, the focus on "voice" as a metaphor has shifted to another angle in composition pedagogy, referring to the growing awareness of and emphasis on personal expression in writing. Personal expression came to be spoken of in terms such as "authentic voice," and the expression of this "voice" was regarded as a natural consequence of selfdiscovery. Steward (1972) explains that when writers begin to find out who they are and what they think, they learn to trust their own voice in writing. Everyone is an individual and is different from others, so each writer's "authorial voice" is unique, notwithstanding the common or shared experiences he or she may share with many other writers (p.9). Under the growing emphasis on issues of personal expression and the unitary self, authentic voice became a buzzword of voice proponents during the late 1960s and early 1970s (Steward, 1972). The current concept of voice was born at this time, with its goals of enhancing self-exploration and fostering more humanistic varieties of academic language.

Not surprisingly, composition pedagogy as developed in the English-speaking world depends in crucial ways on the expression of a "self" that is entrenched in American culture and pedagogical practices, because the purpose of American education is to help students realize themselves and become true individuals (Bowden, 1999; Burnham, 2001). The metaphorical notion of voice, therefore, appears to have developed with strong links to the ideology of the individual in composition pedagogy, an ideology coming from mainstream American society (Ramanathan \& Atkinson, 1999). During the 1990s, voice continued to maintain its allure in English composition pedagogy because it appealed to values that both educators and students already held, or to strong values which had been embedded through the ideology of individualism. Peter Elbow (1994) states that voice helps writers conceptualize some of the intangibles in writing and helps them make concrete such abstractions as meaning, power, and honesty. In Writing with Power (1981), Elbow demonstrates the role of voice in impacting individual writers to act in the world through the use of objective as well as subjective evaluation methods affecting the revision process.

\subsection{Approaches to the Teaching of Writing in Taiwan}

The role of grammar instruction in writing and language teaching has been controversial. Some studies report that to attain advanced proficiency in L2 writing, learners need to attend to grammar in their writing; some studies claim that L2 pedagogy genuinely is concerned with learner proficiency in writing and needs to include the teaching of relevant L2 grammar (Hammerly, 1991). In contrast, in light of the research conducted in L2 learning and acquisition, some scholars claim that overt instruction in grammar does not necessarily lead to direct improvement in language learning (Hinkel, 2002). Although the notion of grammar instruction in writing has attracted criticism, under the circumstance of the test-oriented education system in Taiwan there is little chance for teachers to avoid putting heavy emphasis on explicit vocabulary and grammar instruction, translation methods, memorization of vocabulary and model sentence patterns.

Product-based and writing process approaches compete in second language writing classes and research in Taiwan. Both approaches can be of use to writing teachers to improve students' grammar and writing, depending upon the teachers' teaching methods, goals, and curriculum. Product-based approaches, which focus on producing a finished product, as they are implemented in Taiwan (e.g. Chen, 2001; Sue, 2003) see writing as mainly concerned with knowledge about the structure of language, and writing development as mainly the result of the imitation of input, in the form of texts provided by the teacher (Badger \& White, 2000). In one such product-based approach, instructors mainly focus on accuracy at the sentence level and emphasize paragraph development through particular organizational patterns such as narration, description, classification, and comparison and contrast (Hyland, 2003a). Crucially, as in other product-based pedagogies, in this approach the outcome of the writing process is a single written piece to be evaluated once by an instructor, typically for passing an exam where assessment depends on an inflexible list of factors that are thought to make for good essay writing. This approach has strongly influenced English teaching and curriculum in Taiwan and is still the most widely preferred approach. As noted earlier, many teachers employ this method to accommodate their teaching to the examination system in Taiwan.

Process-based teaching of writing, an approach which focuses on the process of writing, however, shifts this focus from linguistic knowledge such as grammar-related knowledge and textual structure to a focus on writing skills, including planning, drafting and revising. It also emphasizes content, ideas, and the negotiation of meaning (Badger \& White, 2000). In this approach, writing is not considered to be a simple, straightforward process leading to only one single draft. The process approach, in fact, involves a long progression of idea generation, multiple drafts, interaction with other people, and revising and editing (Flower, 1989). Therefore, implementing the process approach in Taiwan is difficult; Sue (2003) claims that many teachers argue that this approach causes confusion and contradictions when used in composition classes in Taiwan. Taiwanese educators tend to believe that students need explicit directions on writing, 
grammar instruction, and feedback on grammatical errors. The application of grammar is a valuable component of writing because it allows students to choose various structures of syntax, adding color and texture to their writing (e.g. Hyland, 2004); but test-based or product-centered approaches do not take advantage of this opportunity. The processbased approach also ignores this valuable component of writing - sometimes even more so than traditional approaches (Badger \& White, 2000).

\subsection{The Importance of Voice}

Voice represents a concept that is widely used yet vaguely defined, though many L2 researchers present a sophisticated version of the concept of voice in their studies. The term "academic personal voice" is significant since graduate students should have their academic personal voice to achieve their learning in the genre of academic writing in terms of "gain[ing] access to ways of communicating that have accrued cultural capital in particular professional, academic and occupations communities" (Hyland, 2003b,p. 24). Many agree that voice plays an important role in academic writing (Ivanic, 1998). However, expressing a skeptical view, Stapleton (2002) argues that extending the discussion about voice may be misleading teachers and students into believing that the expression of identity takes precedence over ideas and argumentation. Helms-Park and Stapleton (2003) suggest that research on L2 academic writing and L2 writing pedagogy would be better directed toward argumentation skills and ideas than voice. Stapleton does raise an important question for further exploration: whether and how voice plays a role in academic writing. However, since he sees these as unanswered questions, he advocates that attention be directed toward more well-known areas of content. Responding to such critiques, Atkinson (2003) mentions that the voice notion should not be dismissed and advocates the need for personal voice or some variety of 'voicist' to be included (Hirvela \& Belcher, 2001). Matsuda and Tardy (2007) conclude that voice is relevant to writing generally and to academic writing in particular. However, they add that this relevance "depends on how voice is defined and how its relevance is measured and interpreted" (p.236).

\section{Research Methods}

This qualitative study set out to explore the viewpoints, as well as the writing practices and developments, of mature Taiwanese writers' development of writing and voices between different academic environments. Creswell (2009) have pointed out that a qualitative study involves an inquiry process aimed at understanding a social or human problem based on building a holistic picture and reporting detailed views of information. Qualitative research methodology is adequate for this exploratory study because of its capacity to gain in-depth and interpretive understanding of the composing process that second language writers employ in different contexts (Creswell, 2007). That is, my research has explored the series of elements or factors that L2 writers feel influenced them while developing their academic writing or constructing their second language writing voice; in particular, I expected to be able to explore the conflicts or problems L2 writers encountered as they entered a context in which voice or positioning is considered central, possibly because this context is socially and culturally imbued with the ideology of individualism, as well as being culturally different from their home country in other ways. This qualitative study included voluntary participants who were faculty in technological institutions and universities located in Central and Southern Taiwan. Three rounds of in-depth face-toface interviews were then used to examine the participants' perceptions on their development of academic writing experiences and problems they have encountered in these areas, as expressed in their own words. The duration of the interview was one hour and the interviews were tape-recorded.

\subsection{Data Collection}

The decision to collect different types of data is particularly useful in this qualitative research because multiple data collection methods are necessary to generate different insights about the phenomenon studied (Cohen \& Manion, 1994). Therefore, the sources of data collection were a questionnaire, individual in-depth interviews, reflective journals, field notes, and textual data collected from published articles or research papers. Interview was the main source of information which was used to answer the research questions. Data was collected by using different collection methods over the period of two months.

\subsection{Interviews}

Lincoln \& Denzin (1998) state that "[t]he interview is the favorite methodological tool" (p.36) in qualitative research because it allows the researcher to get close to people and to hear them talk. In the course of the interview, the researcher and respondents are able to move back and forth in time; to construct the past, to interpret the present, and to predict the future (Lincoln \& Guba, 1985). Clearly, the interview is a useful approach for gathering participants' descriptive data in their own words or voice, and understanding why people do what they do and how they understand their world as they solve a variety of problems (Rubin \& Rubin, 1995).

I conducted three main interviews with an assortment of more and less structured questions. These interviews were what Hatch (2002) and others describe as "semi-structured," which allowed me to investigate the informants' responses seen through interview interactions (p. 94). In addition, specific information was elicited from participants primarily through open-ended questions posed in the initial questionnaire for the study. In the type of interview used in this study, the order of the questions is not determined prior to the interview, so that respondents are permitted to answer in their own ways, and depending on their response, the researcher is able to probe for alternative responses and for clarity during the interviews (Stake, 1995). This manner of questioning has generated rich data collection, as the research of Van Maneen (1990) has demonstrated.

In addition to open-ended questions, I applied another approach that Rubin \& Rubin (2005) suggest. That is, I used three kinds of questions: main questions, probe questions, and follow-up questions. Main primary questions were 
prepared before the interview and asked at the beginning as an introduction to each interview topic, in order to guide the conversation. I asked probe questions when I needed more clarification or more examples about specific issues discussed during the interview. These questions took forms such as, "Could you please tell me more about your thinking on that?" The follow-up questions were asked in the second and third interviews in order to clarify or elaborate upon some core ideas and concepts from previous interviews.

Since all in-depth interview questions of this study revolved around the experiences of the participants in the past or the present time, and some questions were related to their writing experiences while they sought to establish their future professional needs, I was able to develop a holistic viewpoint regarding these Taiwanese writers' academic writing practices. I intended to use this data to elaborate upon the phenomenon for further discussions associated with specific issues such as voice, textual borrowing, and positioning. In the paragraphs that follow, I detail the process and the data that I expected would be produced through these three semi-structured interviews.

\subsection{Participants}

Participants in the present study were purposely selected to ensure that data was collected from a group of mature writers, namely academic writers, with graduate degrees from English-speaking countries, and who had returned to professional positions in Taiwan. Additionally, as the purpose of the study was to hear the voices of individual NNS professional writers in their transition and development of academic writing in English, I ensured that all participants were selected on the basis of six criteria: 1) participants must have a doctoral degree; 2) all participants must have professional writing experiences in English, defined as published research papers and journal articles; 3) they must have finished their undergraduate studies in their home country (Taiwan); 4) they must have positions as assistant professors, associate professors, professors or temporary faculty in Taiwan; 5) they must have experience of studying in an Englishspeaking country; and 6) they must have returned to Taiwan after receiving their degree. In order to protect the anonymity of participants in the study, pseudonyms were used to identify the participants. Table 1 shows the overview of the background of participants.

Table 1. Overview of the Background of Participants

\begin{tabular}{|c|c|c|c|}
\hline $\begin{array}{l}\text { Participants } \\
\text { ( Gender/ position) }\end{array}$ & $\begin{array}{l}\text { Previous writing } \\
\text { experience }\end{array}$ & $\begin{array}{l}\text { Postgraduate studies in overseas } \\
\text { countries ( pursuing degree and } \\
\text { years) }\end{array}$ & $\begin{array}{l}\text { Age } \\
\text { Around }\end{array}$ \\
\hline $\begin{array}{l}\text { Dr. E ( F / Associate. } \\
\text { Pro.) }\end{array}$ & $\begin{array}{l}\text { Academic } \\
\text { professional }\end{array}$ & $\begin{array}{l}\text { MA in English Language and } \\
\text { Literature(3) } \\
\text { Ph.D. in Education (5) }\end{array}$ & 45 \\
\hline $\begin{array}{l}\text { Dr. R (M / Assistant. } \\
\text { Pro.) }\end{array}$ & Personal & $\begin{array}{l}\text { MA in TESOL ( } 2) \\
\text { Ph.D. in TESOL and Composition } \\
(3.5)\end{array}$ & 50 \\
\hline $\begin{array}{l}\text { Dr. K( F/ } \\
\text { Assistant. Pro.) }\end{array}$ & $\begin{array}{l}\text { Personal/ Essay } \\
\text { Academic writing }\end{array}$ & $\begin{array}{l}\text { MA in TESOL (2) } \\
\text { Ph.D. TESOL (4.5) }\end{array}$ & 35 \\
\hline $\begin{array}{l}\text { Dr. T (F/ Assistant. } \\
\text { Pro.) }\end{array}$ & Essay writing & $\begin{array}{l}\text { MED in TEFL (1) } \\
\text { Ph.D. in TEFL (5) }\end{array}$ & 5 \\
\hline
\end{tabular}

\subsection{Data Analysis}

Although all qualitative data analysis is inductive, different theoretical stances and different disciplines have developed particular strategies for data analysis. Basically, analysis of a qualitative study is "the process of making sense out of the data" and a process of "making meaning" (Merriam, 1998, p.178). This study used the qualitative data analysis methods provided by Rubin and Rubin (2005) and the constant comparative method presented by Bogdan \& Biklen (1992). As Bogdan and Biklen describe, data analysis is a process involving systematic searching and arranging of data from interview transcripts, field notes, and other qualitative data collection methods. Therefore, in order to make sense of the recorded interview data, I organized the data by simplifying it into smaller, more manageable units and synthesizing it, searching for self-contained patterns, and discovering information to relay to readers.

After being completely collected, the data were analyzed and interpreted in two stages. In the first stage, I analyzed the data from the interviews independently by identifying responses as they compare against the guiding research questions of the study. Then, in the second stage I engaged in careful reading of the transcriptions, reviewing the data to code and categorize individual statements and passages according to each participant. The participants of this study included four 
Taiwanese writers who had training in academic writing in the United States and have now returned to Taiwan to take up professional positions there. Basically, the interview data was analyzed in stages. In the first stage, I carefully read and re-read the transcripts so as to identify the concepts, themes, patterns, and topical markers in the interviews. I planned to review the data in order to code and categorize individual statements and passages according to the central themes. These themes referred back to the research questions in order to break up and segment the data into simpler, more general categories as I strived to formulate different levels of interpretations and analysis. The two vital thematic areas for data analysis were: 1)Writing Experiences: academic writing development, perceptions of writing academic papers in Taiwan and the U.S., strategies and dilemmas writers encountered; 2) Voice-related Issues: attitudes toward written voice, awareness of written voice in academic writing, cultural and educational background.

\section{Results}

In this section, I only present narratives covering the relevant writing experiences of each participant as they pertain to research questions. Some essential issues will be presented in the discussion section.

\subsection{Dr. E's Writing Experiences and Practices}

Dr. E studied both in Taiwan and Australia. She completed a B.A. and M.A. in English literature in Taiwan and a Ph.D. in Education in Australia. In her high school and undergraduate education, Dr. E explained that she had worked hard to write correct sentences and use grammar properly. During her B.A. and M.A. studies in Taiwan, she had written short papers and a thesis on literature. While writing these papers, she had enjoyed using critical and creative writing styles that allowed her to interpret and analyze aspects of stories from her own perspective and expressing critical views using her own voice.

Dr. E's background in literature, however, left her feeling unprepared for the rhetorical demands of the papers and research domains required in her Ph.D. program. As she put it, "It [i.e. her doctoral area] is social science research paradigm which is totally different from humanit[ies]." To illustrate the difficulties she experienced in her doctoral work, she elaborated: "I received no preparation in my M.A. program which would help me to think critically"; she also noted that she had not received "writing practice related to argumentative writing, rhetorical skills, conference proposals, article introductions, and research papers." As a result, she was barely able to reach her professors' higher expectations (e.g. rhetorical demands, individual thinking in and contributions to her research field); and for a long time, she felt frustrated about her ability to study in the Ph.D. program.

Dr. E took three years to learn the format of academic writing in order to position herself properly in the disciplinary community and to understand the meaning of critical thinking. During her fourth year, while writing her dissertation, she finally met her advisor's requirements. She was very surprised to have a response from him that consisted of one simple sentence--“That is what I want." Commenting on this moment, Dr. E said that, three year after she had started her studies, she "finally understood and reach[ed] my advisor's expectations." Yet even after her long struggle, it seemed that her newfound understandings were not yet solid. She still felt apprehensive about conducting research, writing academic papers, and dealing with the issue of expressing voice in her academic papers.

After graduating from the Ph.D. program, Dr. E gained confidence in writing due to her published works. She pointed out that improvement in writing may occur through one's publications and the feedback of professional peers. Dr. E believed that researchers should not bring their own assumptions, beliefs, values and expectations to their papers, since it was important to meet the demands of publication, including objectivity. Therefore, her writing style has shifted based on reader comments, as she has tried to appeal to various readers or reviewers. In the years after obtaining her degree, she considered several writing strategies which she hoped would help her succeed in having her work published. She mentioned having a critical and creative way to interpret things as important for academic writing; so she has worked to include critical thinking and ideas in her papers. Most importantly, she believed that she needed to position herself as a professional and knowledgeable scholar in the paper; therefore, presenting her knowledge became a high priority for her while writing academic papers. Thus, ultimately, she returns to the idea of holding authority through knowledge and ideas, rather than through the force of her presentation.

\subsection{Dr. R's Writing Experiences and Practices}

Dr. R studied both in Taiwan and the U.S. He earned a B.A. in Applied English in Taiwan and an M.A. in Applied Linguistics as well as a Ph.D. in Composition and TESOL in the U.S. In the early stages of college English writing, he reported that the writing instruction he received in college had mainly focused on narrative; so at this early stage, he had used more colloquial language in his papers rather than academic forms. The papers were primarily first person narratives (e.g. autobiography, reflections, reports, stories, and sometimes literary analyses) that used colloquial vocabulary. His teachers had not explained notions such as genre to the students at this point, but instead had focused primarily on grammar. At this point, he had felt comfortable writing narratives and using linguistic features that reflected a personal voice (first person pronouns I, and we, and colloquial forms) in his papers; but he was using few academic words, and he had no understanding of argumentative form or APA style. Thus when he entered the M.A. program in the U.S, he encountered a confusing new world that required him to meet requirements with which he was unfamiliar.

One difficulty Dr. R encountered involved rhetorical structure. Perhaps because he had never written an argumentative paper, his teachers commented that he relied on his Chinese rhetorical background and thus had trouble with the requisite structure (e.g. the positioning of topic sentences, supporting arguments, and conclusions) for his graduate papers. He comments, "One of the American professors criticized my first paper with the written comment that this 
paper was good at content but not at form." He especially had trouble with research papers. Dr. R also reported that he lacked understanding of the APA style and he had trouble selecting a proper format in academic writing. Here he again offered a recollection about his teachers: "I was confused about [academic format]; but my professor didn't say anything and just asked me to write with APA. I think they assumed that I already knew this writing skill." After two years of academic writing in the master's program, he had learned how to write quantitative studies, but he still had trouble with writing qualitative reports up to the standards expected by the readers on his doctoral committee, and he commented on the stress this caused him:

I [had] to adjust and accept all their comments. . . . [I]t took me so much time to revise what they want[ed] me to do . . . I I still [had] a sense of uncertainty which made me so nervous. Because of this kind of uncertainty, I suffer[ed] lots of pressure while writing... any single sentence and paragraph.

He made progress with APA style. With regard to positioning, he felt that he had made progress during his years of working in the Ph.D. program. He felt that he had been trained to view and interpret material in more flexible, creative and critical ways, expressing his own voice in his texts, but using academic language rather than the colloquial forms of his earlier writing experience. Therefore, when he began writing research papers for his doctoral courses, Dr. R now felt that he could bring his own assumptions, beliefs, values and expectations into his papers, and he felt connected to his writing. Dr. R said that he had begun to write critically, to feel confident in expressing his own ideas in papers, and to understand how to use a personal voice to maintain a sense of authority in his writing. Reflecting on this, he reported that he now felt empowered to write critically and to include his personal views and strong judgments in his papers.

Dr. R believed that the quality of his ideas and knowledge were very important elements for academic writing, and they were also the major sources from which his confidence came, rather than using personal expressions such as the first person "I" in texts. When pressed to elaborate further, he reported that he felt he developed confidence as an academic writer and this stemmed from being able to take a stance of authority in his writing, rather than simply focusing on the first person pronoun or using colloquial vocabulary. After two years of Ph.D. course work, Dr. R felt that he remained confused and conflicted about some features of disciplinary writing which could assist him in positioning himself appropriately in his writing in relation to his professional audiences. He said, "I was struggling with the meaning of 'deep' data analysis and categorizing data effectively while writing my dissertation." Therefore, Dr. R had a hard time reaching his committee members' expectations and keeping his voice while writing his dissertation. However, by the end of the dissertation stage, Dr. R had acknowledged the importance of needing to meet readers' expectations beyond those of his advisor.

\subsection{Dr. K's Writing Experiences and Practices}

Dr. K studied both in Taiwan and in the U.S. She completed a B.A. in English literature in Taiwan and an M.A. and Ph.D. in TESOL in the U.S. Dr. K claimed that her prior writing practices in Taiwan had shaped her early academic writing practices. She further explained that pedagogical approaches in Taiwan have not progressed much past the grammar translation method and the formulaic five paragraph essay over the last 20 years. When she went on to study for the M.A. and Ph.D. in TESOL in the United States, however, she found she was required to perform more advanced tasks in order to write longer papers (e.g. research papers and proposals), and she had trouble mastering the skills needed at this level. The first problem she had was using correct grammar and academic word choice. She shared a comment by one professor, who claimed that reading her un-proofread papers was like receiving "a needle injury in ... [the] eyeball"; this professor went on to say, "I won't be able to read your paper before you see the tutor." Though her earlier training had focused on grammar and form, she was now confronted with a kind of language that she still had not mastered well enough to meet her professors' requirements.

Dr. K also explained that she could not simply translate from English to Chinese. Instead, her professors told her she had to synthesize all of her ideas and categorize them clearly. However, her own focus remained to some extent on issues of form; in particular, she had difficulty focusing on the direct and precise expressions required in English academic writing, and as a result she continued to use Chinese styles. These included circulating through different points rather than progressing in a linear fashion. To help her understand rhetorical conventions, one of her professors explained:

[W]riting is just like making a cake; you have to make one layer by layer: one layer for butter, another for chocolate, the other for nuts. You have to separate them and do not mix them together in the same layer.

Listening to her teacher's advice and imitating the style of published articles, she learned that she needed to "mention one thing each time with some supporting ideas, but not grouping everything together."

A second problem she had was with paraphrasing. Due to having insufficient reading skills, she misinterpreted articles that she used as sources for her papers, a problem that was compounded by her own struggle with finding clear phrasing. Therefore, the meanings in her paraphrasing were somewhat different from the authors' meaning. Aware of this, she explained, "I have no confidence in [my paraphrasing, because] I am not sure if my writing is appropriately expressing the author's ideas or not." To compensate, she opted to use direct quotation. Opting to use more quotations solved her troubles with paraphrasing, but it also raised another. She realized that when she "simply restate[d] others' ideas and view[s]," she was unable "to offer an original insight or interpretation." As a result, instead of infusing her 
own ideas and voice into her writing, she adopted an impersonal tone that relied on other authors' voices (quotations) in her papers instead of her own. Another professor questioned me where my own ideas are and tried to help by showing me a paper with four citations, but that confused me still more. Instead of understanding the need to incorporate her own voice, she mistakenly focused on the number of references as a measure of her authority. Despite her trouble with voice, she continued to progress through her M.A. and on to her Ph.D. program through a reliance on modeling. When the need to interpret quotations arose, she carefully used modal words, "to hide [her] uncertainty... under confident statements."

After she graduated from her Ph.D. and attempted to publish, she explained that she felt able to meet the demands of grammar, word choice, sentence variety, and rhetorical styles. However, she published few articles because she continued to have trouble balancing the need to cite sources with the competing goal of expressing her own ideas and maintaining her own authority and voice as author. Reflecting on her writing experiences, she explained, "[W]riting a good paper includes a clear purpose and intention, expressing writers' ideas clearly and in the correct format." However "writing shouldn't be only rhetorical. It should be something else." A "student should be able to express her personal voice and . . . creativity without any rules and constraints." And thus when giving feedback to her own students, she focused more on students' ideas and less on their use of correct grammar and format in order to foster their development of their own voices.

\section{4 Dr. T's Writing Experiences and Practices}

Dr. T pursued a B.A. in German in Taiwan but wanted to pursue graduate degrees in TEFL in the U.K. To do this, she knew she needed to improve her English writing skills in order to attain a high enough score on the TOEFL TWE to be accepted to a U.K. university; for this reason, she attended a cram school in Taiwan after completing her B.A. degree. At the cram school, she learned skills that helped her to get an adequate score on the TOEFL TWE (e.g. practice with thesis statements, topic sentences, supporting ideas, and conclusions for argument essays). However, when she arrived at the university in the U.K., she found her writing skills were insufficient for her first year of graduate study which required more advanced writing skills; for instance, the ability to write critically within rhetorical conventions in a way that expressed one's own opinions was required. As a result, the first writing assignment she submitted in her M.A. program was returned for revisions. To improve the paper, her instructor told Dr. T that she needed to work on the conventions of academic writing (e.g. argumentative style). Her instructor also told her she needed to be able to go beyond simply paraphrasing and summarizing and show she could think critically and assertively to express her own voice and opinions.

Attempting to meet her professor's expectations, Dr. T rewrote the paper several times and made progress. Dr. T felt that her ability to write well-organized arguments had improved and she had learned to assertively express her voice: "When I wrote something from my own opinions or some creative ideas, I got a good grade for that paper, so I [was] pretty sure that professors [were] looking of my personal ideas and voice." Dr. T also explained that with her teachers' guidance and instruction, she continued to expand her abilities. She found she could, for example, write in different genres where she could critically interpret other authors' perspectives and then forward her own opinions using her voice.

Once in her Ph.D. program in the U.K., Dr. T was again encouraged to use her own voice in her course assignments. Instead of simply reiterating what she had read in others' works through paraphrasing or quotations, she was again encouraged to engage in critical thinking and express her own ideas. Her professor, however, offered a cautionary note that, as a student researcher, Dr. T should balance her ideas by hedging her judgments with the modal verbs would, should and could, and she should try to choose objective language for the same reason. To compensate and reduce negotiations with her professor, Dr. T learned to hide behind other authors with similar ideas when writing the literature review for her dissertation, and then only later come forward with her own unhedged assertive voice in the qualitative data analysis section of her dissertation. Dr. T. clearly enjoyed writing her own ideas more than feeling that she had to conceal her voice in her writing. Accordingly, after leaving graduate school and moving on to publishing, she included fewer sources in her literature reviews, and opted to take more assertive stances in putting her own ideas forward:

I understood [that] readers' expectations [about including sources] are very important, but I did not think too much about this point. . . . I wanted my readers to accept my ideas and make this world better. I felt it's the reader's responsibility to be interested in the topic or not.

Dr. T soon found, however, that her strategy of not synthesizing other's ideas with her own did not meet with success, as her papers were not accepted or she was asked for revisions. To appease editors, she again adopted the strategic pattern she used in her dissertation: that is, including other authors with similar ideas in her literature review, and then coming forward with her own voice in the qualitative data analysis section of her papers.

As she began teaching in Taiwan, Dr. T found that the education system had much different ideas about what was important than the ones she had learned in her graduate education. Her teacher colleagues were focusing on grammar exercises and paragraph writing with no emphasis on academic writing, critical thinking, or expressing one's voice. She felt frustrated because she wanted to "empower students" by giving them opportunities to write more academic papers. She even gathered colleagues and conducted action research studies to prove her point; but in the end, she felt that her ideas "were just ideas on papers." The reason for her discouragement was her supervisors' position: when Dr. T proposed research plans or changes in teaching focus, these supervisors replied that the curriculum did not allow 
enough time for such methodology. They pressured her to abandon her other plans and to focus on grammar, language, and paragraph forms in her writing classes. As a result, although she strongly believed in helping students to write more academically, think critically, and express their own voices, she succumbed to administrative pressure to teach the restricted curriculum.

Reflecting on her educational and professional experiences, Dr. T. said she was pleased to have learned to connect herself to her papers by viewing things in a variety of ways, expressing her own ideas comfortably, and bringing her assumptions, beliefs, values, and expectations into her Ph.D. and publishing. She was also pleased that the voice she found academically enriched her daily life, as she felt more able to think critically about day-to-day life matters and was more comfortable expressing her opinions openly. However, she expressed regret over what little impact her ideas had on her teaching environment. Reflecting on this last point, she came to the conclusion that the only benefit of the research she had published about her teaching situation was to "credit" herself, as she had little belief that anyone was "going to carry out our suggestions."

\section{Discussion}

Given the results of this study, I would like to answer research questions using several prominent ideas which emerged from the participants' interviews regarding their development of academic writing and growing awareness of their development of voice in Taiwan and in overseas countries.

\subsection{Academic Writing Development in Taiwan}

The results of this study show that the majority of the participants related their early development of English writing to the product-oriented teaching approach, to writing practice, and to the text-oriented educational system in Taiwan, which they used as their point of reference. In this study, the four participants credited their training in Taiwan for their improvement in language proficiency; however, they did not feel that the training and writing practice they experienced in Taiwan had helped them to improve their general academic writing skills, in particular with regard to voice, or positioning.

Two major elements that participants felt had affected their writing development are writing pedagogy and writing practice. The first two of these can be treated together, as they intertwine and are both rooted in classroom practice in Taiwan. The Taiwanese L2 instructors who taught this study's participants used traditional writing pedagogies emphasizing such components as mastery of writing mechanics, the structure of language, correctness of forms, and grammatical accuracy. This led to a writing style that prioritized imitation in the language learning process and overemphasized grammar in the writing class. One result was that these Taiwanese developing writers feel that they faced a great challenge to develop a familiarity with academic writing genres and academic writing strategies. In particular, this emphasis on teaching grammar, to prepare students for the proficiency tests, may cause substantial problems for students who are preparing to study abroad, if they enter a new context in which they lack the skills or creativity to write academically. Furthermore, this approach to writing pedagogy has downplayed the important concept of writing as a social act and writing as the communication of ideas; that is, students in such a system are not exposed to the idea that academic writing involves expressing "ideas and values through a writer's choice of words and styles of writing” (Shay, Moore \& Cloete, 2002, p. 249). Students are not encouraged to express their own unique thoughts or to problem-solve. Rather, they are encouraged to apply writing skills such as "memorizing vocabulary, model sentences, and paragraphs for college writing" (Dr. K). As Dr. T said, "the writing skills I had learned and the topics I wrote about were not academic enough for my first year of graduate writing." As we can see, Taiwan's writing pedagogy is not guided by the kind of goals that can lead students to understand the importance of academic writing conventions and format or to develop their own thoughts or personal voice, even in the disciplinary community.

Narrative writing practice is another element affecting the participants' development of academic writing. As Drs. E, T and $\mathrm{K}$ mention, narrative writing was the predominant writing style they experienced in high school. Through narrative, participants actually included their personal voices and ideas while composing their writing; however, the study results demonstrate that they seem to still "lack the confidence to express their ideas in academic writing" (Dr. K). Even though they had relatively fewer constraints in their later training, and were encouraged to develop a "strong and direct voice" (Dr. T), their writing practice did not help them to develop an awareness of when to " us[e] a strong voice while writing academically" ( Dr. T). From their writing practice and development in the L1 context, it also seems that their academic writing ability was not adequate to meet the expectations demanded by the pedagogy practiced at the graduate level in Western culture.

\subsection{View of Development of Academic Writing in Overseas Countries}

Due to the influences of prior writing practice and writing experiences in Taiwan on the four participants, they still had to process and learn how to write within the norms particular to given disciplines when they began to study overseas. In fact, after embarking upon their graduate studies, every participant viewed their experiences with writing development and perceived their difficulties in academic writing differently.

\subsubsection{Knowing How to Write for a Disciplinary Community}

Some researchers stress how important it is for L2 writers to legitimatize and position themselves in academic communities (Hirvela \& Belcher, 2001; Ivanic and Camps, 2001; Matsuda, 2001). Comments related to this point surfaced at many points in the interviews. From the interview data presented in above section, the four participants remarked that they still had to process and learn how to write within the norms particular to given disciplines, since they 
were expected to be active participants in their professional discourse communities. To meet this goal, again, they realized that they needed much expertise that had not been a part of their early training as developing writers. They commented that they had no knowledge of writing skills or writing styles in the first year of graduate study, mentioning specific elements such as familiarity with APA style (Dr. R) and citations (Dr. K). They also were not aware of rhetorical matters such as how to use sophisticated wording (Drs. E, K and T), or of how to summarize and synthesize (Dr. T ) in order to clearly express meanings or ideas (Dr. T). Once again, these are challenges faced by every graduate student; however, the present study looks at the way they were perceived and met by one special group of current Taiwanese professionals.

After a few years of academic writing experiences, the four participants all stated that they had improved in their understanding of how to express themselves adequately within their disciplinary arena. They had learned how to consciously write within the norms particular to given disciplines in their academic communities and how to use sophisticated features in their professional writing. For example, Drs. R and E especially noted that they had needed to change their writing styles based on feedback from readers or editors, and Drs. E and T mentioned that they had improved their ability to meet readers' expectations. Drs. R and E also further stated that they had progressed in their understanding of negotiation and communication. Drs. R, E and T all reported that they had developed in their ability to understand how features of disciplinary writing can play a role in assisting them to position themselves appropriately in relation to their professional audiences while writing academically.

The participant writers understood that writing for academic contexts is not simply related to writing skills or rhetorical issues such as "synthesizing all ideas into writing" (Dr. T), "writing in the correct format, citing sources" (Dr. K), or "organiz[ing] and edit[ing]" (Dr. E). However, academic writing becomes much more difficult and complicated if " [it is] not a skill issue but a matter of communicating with people using one's own knowledge and one's own communication skills" (Dr. E). If one takes into consideration social, political, cognitive, and cultural factors, it becomes an even more complex issue. Therefore, academic writing may become a difficult job for L2 writers "if they try to incorporate their professional writing skills, knowledge and critical thinking into academic writing" (Dr. R). To be successful L2 mature writers, they must write and think differently and select an appropriate way to position themselves in texts. The learning and adjustment that these mature writers made in successfully completing their graduate study, and then returning to work in their original Taiwanese context, represents quite a complex journey, and one whose stages they had become quite aware of, as the richness of their own commentary shows.

\subsubsection{Readers' Expectations}

As Hyland (2007) claims, writing is a social activity which requires one to engage in a variety of relevant writing experiences and to investigate different purposes and readers. The participants defined their readers in professional terms, as those who were from the same academic or disciplinary communities (Dr. E), or as "professors and editors" (Dr. R). The interview data showed that Drs. $\mathrm{R}$ and $\mathrm{T}$ realized their Western readers' strict requirements regarding critical thinking and clear expression; consequently, these two participants included strong arguments and strong, clear personal voice in their texts. In fact, Drs. $\mathrm{R}$ and $\mathrm{T}$ seemed to associate their usage with their greater awareness of readers' expectations. However, on the whole, the participants seemed not to have an understanding of reader expectations that was broad enough or specific enough to help them to write with particular editors/reviewers' expectations in mind. Although they had changed and grown in so many ways, this was one area where their development seemed still to be a work in progress.

\subsection{Growing Awareness of Their Development of Voice}

After a few years of study in overseas countries, the participants identified several essential elements that they believe influenced their developing voice in academic writing. The first thing they mentioned is related to empowerment. Drs. $\mathrm{R}$ and $\mathrm{T}$ were able to view things from various perspectives and develop a strong voice in their writing when their teachers empowered them to write. Dr. R indicated that he could "transform this power into his writing." Dr. R's view can be approximated to Elbow's view of voice as the release of a writer's inner self; writers find their own voice through empowerment and self-expression. The participants' testimony supports the belief of many writing teachers that writers in general, and L2 writers in particular can develop their writing if writing teachers can empower and encourage them to express their thoughts.

Apart from the issue of empowerment, Drs. E and T also point out that their professors' expectations or schools' requirements made them value things differently. For example, due to Drs. E, T and R's awareness of being individual and independent researchers/writers with critical views and ideas in their writing, they gradually started to write something with their own opinions confidently and to develop a stronger voice and varied perspectives in their writing. However, not all participants spoke of this kind of learning. By contrast, Dr. E felt that their voices were based on the quality of the evidence they presented. In any case, all agreed that positioning themselves as knowledgeable scholars with a scholarly voice is very important.

Their improving academic writing abilities helped them to develop more confidence over time through gaining more control over the academic voice in their texts. These writers had been learning to "select proper genres for expressing ideas effectively" (Dr. R) and to find ways to express their own knowledge (Drs. R and E) in their disciplinary communities. That is, when these L2 mature writers began to figure out what rules they had to follow, they started to interact with written texts in a more sophisticated way and to increase their awareness of language usage in diverse contexts. 
As some researchers state, as long as L2 writers can perceive a wider readership and become sensitive to their readers' expectations, they can easily legitimatize and position themselves in academic communities (Hirvela \& Belcher, 2001; Ivanic and Camps, 2001; Matsuda, 2001). The writers in this study had worked to understand their readers and their ideologies, interests, research fields, and expectations. The four participants felt that with this understanding, they could choose and adjust their voices and communication with readers effectively and confidently. However, some participants expressed ambivalence about this need. In particular, Dr. R stressed that in his opinion, L2 writers should not reorient themselves to values found in Western culture to the point that they must leave their own beliefs and ideologies behind. In trying to meet reader expectations, a number of tricky questions arise: Whose voice takes over? Whose meaning is heard? Who has the power to repopulate or resist another's words? When writers identify their professor as their main reader and feel they need to reflect the professor's ideologies in their texts, power is unequally distributed. To some extent, the results of this study hints at this danger, since the professor was often listed as the audience for graduate level papers.

\subsubsection{Voice and Positioning for Professional Needs}

The adjustments and learning that these participants experienced in their Western graduate training had to be further modified in most cases once they returned to Taiwan; this modification involved both their practice as teachers and their writing as researchers. First, it was a challenge to the participants to reflect their graduate training in their own teaching. Drs. R and K said that their voice development in the U.S. greatly influenced their teaching methods; therefore, they now emphasize the concept of voice in their writing classes and in evaluating student writing, in order to develop students' voice and critical thinking. However, this position cannot be easily maintained and defended, given official policies in many Taiwanese institutions. Even though Drs. R and K stressed the need to integrate voice in L2 writing pedagogy in Taiwan, they also said that they felt compelled to give priority to language skills or forms in their teaching approaches due to the strict time limitations, the goals of their school's curriculum, and school policies. Second, since returning to their teaching positions, these L2 writers are required to write publishable papers in their teaching position. Here, too, official policies play a role: they are supposed to adopt or adjust to new forms, writing styles, and voice in their texts based on their schools' policies, which include preferences for research design (quantitative, qualitative or mixed). The voice they developed in their overseas studies stressed critical thinking, professional knowledge, and keeping authority in their papers. However, in Taiwan, publication is just another practice to earn professional credit; personal voice is not felt to be an essential component for publication. Consequently, the majority of these L2 mature writers did not feel that the concept of personal voice is important for their academic writing in Taiwan, although they did value learning ways of positioning themselves as researchers/scholars, a task which they still could not manage well.

Once again, the competing demands of the Western graduate world and the professional world in Taiwan have caused these writers to each find his or her own compromise, valuing what they learned in their graduate work, and yet recognizing the need to now exist within the demands of their professional situations in Taiwan. As it became clear numerous times from this study's results, these writers have faced not one, but two challenging cultural transitions in their careers.

\section{Conclusion and Suggestions}

In negotiating their transition between different academic environments, the Taiwanese writer participants in this study faced issues such as their view of academic personal voice, their prior academic writing practices and their challenges with academic writing. Although L2 writers encounter problems and challenges at the beginning of their graduate studies, the present study has confirmed that they can develop their academic writing, skills, critical thinking or voices through engaging in academic writing practices, experiencing the processes of socialization, and receiving support from schools, professors, and peers. The ideas L2 writers developed during their education were reinforced after they went to their academic career. That is, L2 writers' development of academic writing and their academic voice benefits their future academic career in terms of successfully publishing their papers, expressing ideas, and increasing their awareness of their readers and their ideologies, interests, research fields, and expectations. L2 writers grow to understand the need to be aware of choosing and adjusting their voices and communicating with readers effectively and confidently, which helps them to present their ideas clearly and to be able to supply an extensive and scholarly literature review with comprehensive methodology and results, and in a form and style common to the discipline. There is clearly a gap in L2 research to display how mature writers move to overseas countries to study and adopt new writing styles and then move back to their home countries. Therefore, I would recommend that researchers make analysis explicit in association with L2 writers' academic writing development, teaching pedagogies and educational systems in different contexts, and extend their understanding of L2 writers' development of academic personal voice through the processes of revision and socialization. In particular, detailed study of an area such as L2 writers' needs for future publication may provide a great contribution to the fields of second language writing, language acquisition, curriculum design and the educational system (including undergraduate and graduate programs) in Taiwan and in the United Sates. I would also suggest that L2 researchers explore L2 writers' hopes and attitudes regarding acquisition of an L2 voice in both L1 and L2 contexts. More studies regarding L2 writers' needs to acquire voice from L2 to L1 contexts should be added to the L2 writing research field. These studies can help L2 researchers to enrich their understanding of how and what elements or problems may affect L2 writers in expressing their L2 voice and their voice-related experience after they come back to Taiwan. 


\section{References}

Atkinson, D. (2001). Reflections and refractions on the JSLW special issues on voice. Journal of Second Language Writing, 10, 107-124.

Atkinson, D. (2003). Writing for publication/writing for public execution: On the (personally) vexing notion of (personal) voice. In C. P. Casanave \& S. Vandrick (Eds.), Writing for scholarly publication: Behind the scenes in language education (pp. 159-175). Mahwah, NJ: Erlbaum.

Badger, R., \& White, G. (2000). A process genre approach to teaching writing. ELT Journal, 54(2), 153-160.

Belcher, D., \& Hirvela, A. (Eds.). (2001). Special issue on voice in L2 writing. Journal of Second Language Writing, 10, 1-2.

Bogdan, R., \& Biklen, S. K. (1992). Qualitative research for education. Needham Heights, MA: Allyn \& Bacon.

Bowden, D. (1995). The rise of a metaphor "voice" in composition pedagogy. Rhetoric Review, 14, $173-188$.

Bowden, D. (1999). The mythology of voice. Portsmouth, NH: Boynton/Cook Heinemann.

Burnham, C. (2001). Expressive pedagogy: Practice/ theory, theory/practice. In G. Tate, A. Rupiper., \& S. Schick (Eds.),

A guide to composition pedagogies (pp. 92-112). New York: Oxford University Press.

Chen, D. W. (2001). The identity crisis of EFL composition instruction in Taiwan. Paper presented at the $18^{\text {th }}$

Conference on English Teaching and Learning in the Republic of China, Taipei.

Cohen, M., \& Manion, L. (1994). Research methods in education (4th ed.). London: Routledge.

Cortazzi, M., \& Jin, L. (1996). Cultures of learning: Language classrooms in China. In H. Coleman (Ed.), Society and the language classroom (pp. 169-206). Cambridge, England: Cambridge University Press.

Creswell, J. W. (2007). Qualitative inquiry \& research design (2nd ed.). Thousand Oaks, CA: Sage.

Creswell, J. W. (2009). Research design: Qualitative and quantitative approaches (3rd ed.). Thousand Oaks, CA: Sage.

Elbow, P. (1981). Writing with power. New York: Oxford University Press.

Elbow, P. (1994). Introduction. In P. Elbow (Ed.), Landmark essays on voice and writing (pp. xi-xvii). Davis, CA:

Hermagoras Press.

Flower, L. (1989). Cognition, context and theory building. College Composition and Communication, 40, $282-311$.

Gee, J. P. (1996). Social linguistics and literacies: Ideology in discourse. Bristol, PA: Routledge.

Hammerly, H. (1991). Fluency and accuracy. Clevedon, UK: Multilingual Matters.

Hatch, J. A. (2002). Doing qualitative research in educational settings. Albany: State University of New York Press. Heath, S. B. (1991). The sense of being literate: Historical and cross-cultural features. In R. Barr, M. L. Kamil, P. B. Mosenthal, \& P. D. Person (Eds.), Handbook of reading research (Vol. 2, pp. 3-25). New York: Longman.

Hinkel, E. (2002). Teaching grammar in writing classes: Tenses and cohesion. In E. Hinkel \& S. Fotos (Eds.), New perspectives on grammar teaching in second language classrooms (pp. 181-198). Mahwah, NJ: Erlbaum.

Hirvela, A., \& Belcher, D. (2001). Coming back to voice: The multiple voice and identities of mature multilingual writers. Journal of Second Language Writing, 10(1-2), 83-106.

Hyland, K. (2003). Second language writing. New York: Cambridge University Press.

Hyland, K. (2004). Genre and second language writing. Ann Arbor: University of Michigan Press.

Hyland, K. (2007). Genre pedagogy: Language, literacy and L2 writing instruction. Journal of Second Language

Writing, 16, 148-164.

Ivanic, R. (1998). Writing and identity: The discoursal construction of identity in academic writing. Amsterdam: John Benjamin.

Ivanic, R., \& Camps, D. (2001). I am how I sound: Voice as self-representation in L2 writing. Journal of Second Language Writing, 10, 3-33.

Leki, I., Cumming, A., \& Silva, T. (2008). A synthesis of research on second language writing in English. New York: Routledge.

Lincoln, Y., \& Denzin, N. (1998). Collecting and interpreting qualitative materials. Thousand Oaks, CA: Sage.

Lincoln, Y. S., \& Guba, E. G. (1985). Naturalistic inquiry. Newbury Park, CA: Sage.

Matsuda, P. K. (1998). Situating ESL writing in a cross-disciplinary context. Written Communication, 15(1), 99-122.

Matsuda, P. K. (2001). Voice in Japanese written discourse: Implications for second language writing. Journal of Second Language Writing, 10(1-2), 35-53. 
Matsuda, K. P., \& Tardy, M. C. (2007). Voice in academic writing: The rhetorical construction of author identity in blind manuscript review. English for Specific Purposes, 26, 235-249.

Maxwell, J. (1996). Qualitative research design: An interactive approach. Thousand Oaks: Sage.

Merriam, S. B. (1998). Qualitative research and case study application in education. San Francisco: Jossey-Bass.

Merriam, S. B. (2002). Qualitative research in practice: Examples for discussion and analysis. San Francisco: JosseyBass.

Prior, P. (2001). Voice in text, mind, and society: Sociohistoric accounts of discourse acquisition and use. Journal of Second Language Writing. 10(1-2), 55-81.

Ramanathan, V., \& Atkinson, D. (1999). Individualism, academic writing, and ESL writers. Journal of Second Language Writing, 8(1), 45-75.

Rubin, H. J., \& Rubin, I. S. (1995). Qualitative interviewing: The art of hearing data. Thousand Oaks, CA: Sage.

Rubin, H. J., \& Rubin, I. S. (2005). Qualitative interviewing: The art of hearing data (2nd ed.). Thousand Oaks, CA: Sage.

Shay, S., Moore, R., \& Cloete, A. (2002). Roles under construction: The intersection of writer agency and task design in South Africa. In D. Foster \& D. Russell (Eds.), Writing and learning in cross-national perspective: Transitions from secondary to higher education. Mahwah, NJ: National Council of Teachers of English and Lawrence Erlbaum.

Stake, R. E. (1995). The art of case study research. Thousand Oaks, CA: Sage.

Steward, D. (1972). The authentic voice: A pre-writing approach to student writing. Dubuque, IA: Brown.

Steward, D. (1972). The authentic voice: A pre-writing approach to student writing. Dubuque, IA: Brown.

Sue. S. M. (2003, November). Product-Oriented or Process-Oriented Approach Toward Teaching ESP? - in the Case of an EFL Nursing English Course. In Yui-nam Leung (Chair), Curriculum Reform in EFL. Symposium conducted at the $12^{\text {th }}$ International Symposium on English Teaching, Hsinchu.

Tang, R., \& John, S. (1999). The 'I' in identity: Exploring writer identity in student academic writing through the first person pronoun. English for Specific Purposes, 18, 23-39.

Van Manen, M. (1990). Researching lived experience: Human science for action sensitive pedagogy. Albany, NY: State University of New York Press. 